ORIGINAL ARTICLE

\title{
Diffusely increased bone scintigraphic uptake in patellofemoral pain syndrome
}

\author{
J E Näslund, S Odenbring, U-B Näslund, T Lundeberg
}

Br J Sports Med 2005;39:162-165. doi: 10.1136/bjsm.2004.012336

See end of article for authors' affiliations

....................

Correspondence to: Jan E Näslund, Karolinska Institutet, Department of Physiology and Pharmacology, Eldarevagen 5 Kristianstad 29144 Sweden; i.naslund@ mailbox.calypso.net

Accepted 6 April 2004
Objectives: Painful disorders of the patellofemoral joint are one of the most frequent complaints in orthopaedic and sports medicine. The aims of this study were to determine whether bone scintigrams of patients suffering from patellofemoral pain syndrome (PFPS) show diffuse uptake and in what bony compartment of the knee uptake, if any, was localised.

Methods: Fifty eight patients with chronic PFPS were examined. All patients underwent a detailed clinical history and a thorough physical examination of the knee. Anterior and lateral static images of both knees

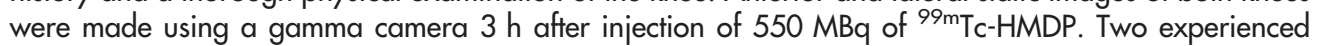
radiologists visually evaluated the scans blindly and separately. As 51 patients had bilateral pain, 109 painful knees are included in the results.

Results: Diffuse uptake on bone scintigrams was found in 48 knees in 30 of the patients. In 33 knees the uptake was localised to only one bone compartment, in 10 knees diffuse uptake was found in two of the bones forming the knee joint, and in six knees all three bone compartments (the distal femur, the patella, and the proximal tibia) exhibited diffuse uptake.

Conclusions: Scintigrams of approximately half of the patients with PFPS will show diffuse uptake in one or more of the bony compartments of the knee joint and radioactive tracer accumulation will occur as often in the proximal tibia as in the patella.
$\mathrm{P}$

atellofemoral pain syndrome (PFPS), also called anterior knee pain (AKP), is one of the most common musculoskeletal disorders ${ }^{12}$ and is reported to affect $15-33 \%$ of the adult population and $21-45 \%$ of adolescents. ${ }^{3}{ }^{4}$ Athletes and non-athletes of both genders are affected. ${ }^{5}$ Among adolescents the incidence is reported to be higher for girls. ${ }^{45}$

PFPS is characterised by pain in the front of the knee, which is often worsened by climbing or descending stairs and by sitting for long periods. There has been no consensus on the definition, classification, assessment, diagnosis, or management of PFPS. ${ }^{6}$ The literature suffers from a lack of standardisation in terms of diagnoses, pain scales, small sample size, absence of blinding, absence of stratification for severity, duration of symptoms, and patient age. Although the cause of PFPS is obscure, it has been generally accepted as being secondary either to the presence of chondromalacia or to patellar malalignment. Studies, however, have reported that chondromalacic changes can be asymptomatic but also that patients with normal articular cartilage can experience AKP. ${ }^{7}$ Reports have also questioned a causal relationship between malalignment and knee discomfort in the majority of PFPS patients. ${ }^{12}$ A different aetiology that takes the pain mechanism into consideration has been proposed by Dye et al. ${ }^{7}$ The authors suggested that PFPS may be attributed to a possible loss of both osseous and soft tissue homeostasis. Patellofemoral synovial and fat pad irritation secondary to mechanical or biochemical factors are reported to be a common cause of pain. ${ }^{8}$ High intraosseous pressure has been suggested as a pain mechanism. ${ }^{9}$ Although PFPS is considered to be one of the most typical forms of nociceptive pain, a contribution of a neurogenic mechanism has also been mentioned..$^{10}{ }^{11}$ Merchant ${ }^{12}$ suggested that one subgroup of PFPS was reflex sympathetic dystrophy of the patella. Butler-Manuel $^{13}$ reported an involvement of the sympathetic nervous system in PFPS.

Bone metabolism and bone remodelling can be evaluated by specific bone seeking radionuclides in a scintigraphic measurement. A positive bone scintigraphy indicates an increase in bone metabolism, but the method cannot determine whether the final result will be a net loss or a net gain in bone. A pathophysiologically increased bone scintigraphy indicates an aetiological relationship between the area with increased bone metabolism and the patient's symptoms. The method can distinguish between localised skeletal conditions, such as stress fractures in the bone, and diffuse increased bone turnover.

Bone scintigraphy has been suggested as one method that can be used in the evaluation of patients with AKP because it depicts physiological features whereas radiography presents biomechanical information. ${ }^{14-16}$ Studies have reported tracer uptake to be located in the tibiofemoral compartment, the patellar compartment, and both. ${ }^{17} 18$

The aims of this study were to determine whether the bone scintigrams of patients suffering from PFPS show diffuse uptake and in what bony compartment in the knee the uptake, if any, was localised.

\section{METHODS}

Information about our clinical study was sent out to the orthopaedic departments in two local hospitals and to 12 local health care centres. Fifty eight patients, who fulfilled the inclusion criteria, gave informed consent to the study. The study was approved by the research ethics committee of the Faculty of Medicine, University of Lund.

\section{Patients}

Inclusion criteria

Patients aged 20-50 years were included in the study in order to avoid misinterpretations in the scintigraphic assessments due to immature bone tissue or osteoarthritis. Patients were

Abbreviations: $A K P$, anterior knee pain; $B M D$, bone mineral density; MTSS, medial tibial stress syndrome; PFPS, patellofemoral pain syndrome 
included if they had activity induced pain for more than 6 months, in two out of the following three situations: (i) when climbing stairs; (ii) on squatting; or (iii) after prolonged sitting. Patient characteristics are given in table 1.

\section{Exclusion criteria}

Patients were excluded if the clinical examination revealed any symptoms suggesting other pathology of the knee joint such as ligament or meniscus tears, synovial plica, tendinopathia, apophysitis, osteoarthritis, osteochondritis dissecans, neuroma, or fat pad impingement. Pathology discovered on radiographic or scintigraphic examinations also led to exclusion. Diffuse uptake on scintigraphy was not regarded as pathologic. Focal uptake patterns were excluded but were only found in one of the patients originally examined. ${ }^{19}$

\section{Scintigraphy}

Static anterior and lateral images of both knees were obtained using a gamma camera $3 \mathrm{~h}$ after injection of $550 \mathrm{MBq}$ of ${ }^{99 \mathrm{~m}} \mathrm{Tc}-\mathrm{HMDP}$ (fig $\mathrm{l}$ ). The scans were visually evaluated blindly and separately by two experienced radiologists who then reached a consensus.

\section{Statistics}

Data are presented as binomial: diffuse uptake or no diffuse uptake.

\section{RESULTS}

Of the 58 patients, seven experienced unilateral pain and 51 bilateral pain. A total of 109 painful knees are included in the study.

Diffuse uptake on bone scintigraphy was found in 48 knees $(48 / 109,44 \%)$ in 30 patients $(30 / 58,52 \%)$. In 33 knees, uptake was localised to only one bone compartment, in 10 knees diffuse uptake was found in two of the bones forming the knee joint, and in six knees all three bone compartments (the distal femur, the patella, and the proximal tibia) exhibited diffuse uptake (fig 2).

When diffuse uptake was found to be distributed into the bony compartments, the patella was the bone that was most affected. Of the 48 affected knees, uptake in the patella was found in 27, uptake in the proximal tibia in 25 , and uptake in the distal femur in 19. Uptake in the femur and the tibia only occurred in the condyles.

None of the scintigrams of the seven patients reporting unilateral pain exhibited any diffuse uptake at non-painful sites.

\section{DISCUSSION}

In this study we were able to confirm previous studies reporting diffuse uptake on bone scintigraphy of patients diagnosed with PFPS. We found that the scintigrams of $44 \%$ of the painful knees and $52 \%$ of the patients showed diffuse uptake. This is in agreement with previous studies ${ }^{13} 1517$ which reported uptake in $40-55 \%$ of the patients.

\begin{tabular}{|lllll|}
\hline Table 1 & Patient characteristics & & & \\
\hline & Total & Men & Women \\
\hline Subjects ( $n$ ) & 58 & 24 & 34 \\
Age (years) & 33.9 & 34.4 & 33.5 \\
Bilateral pain (n) & 51 & 22 & 29 \\
Pain duration (years) & 8.4 & 8.3 & 8.5 \\
Pain on climbing stairs (n) & 57 & 23 & 34 \\
Pain on squatting (n) & 57 & 24 & 33 \\
Pain after sitting for long periods (n) & 47 & 20 & 27 \\
Tegner's activity scale, work (0-10) & 2.6 & 3.0 & 2.4 \\
Tegner's activity scale, sport (0-10) & 3.5 & 3.6 & 3.4 \\
\hline
\end{tabular}

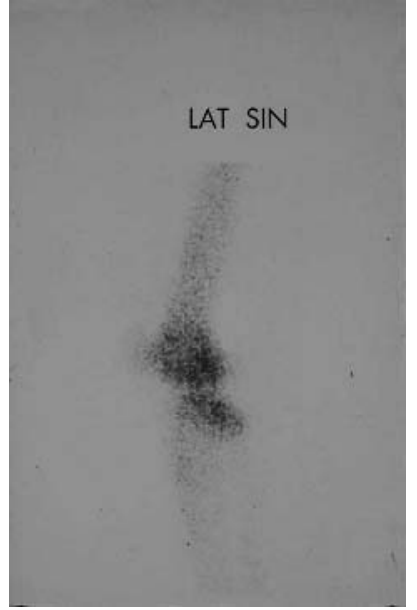

Figure 1 Bone scintigram with diffuse uptake in the left knee.

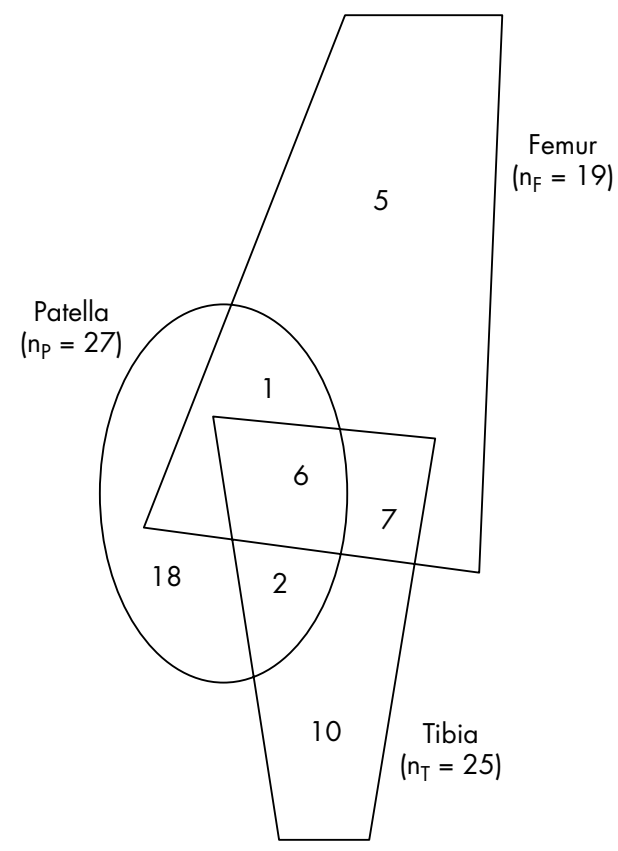

Figure 2 Localisation of diffuse uptake on scintigraphy.

Loberboym et al, ${ }^{20}$ using single photon emission computed tomography, found diffuse and focal uptake in $100 \%$ of the patellae and in $67 \%$ of the distal femurs examined.

For ethical reasons, we examined no control group scintigraphically in our study. However, diffuse uptake in control groups is reported to be between $4 \%$ and $9 \% .{ }^{15}{ }^{17}$

Historically, use of bone scintigraphy to gather information on the knee has been limited. ${ }^{99 \mathrm{~m}}$ Tc labelled methylene diphosphonate, which has an affinity for hydroxyapatite and is correlated to the activity of the osteoblasts, has been used. Increases in osteoblastic activity as low as $10 \%$ can be detected with this method. ${ }^{21}$ Sensitivity is reported to be about $95 \%$, but specificity is poor as every disease or injury with increased bone metabolism will be detected. ${ }^{22}$ The ability of bone scintigraphy to detect, with high sensitivity, early changes in bone metabolism and bone vascularisation is the basis of its clinical usefulness. ${ }^{22}$

It is not known whether the diffuse uptake observed on bone scintigrams of patients with PFPS is related to the cause or is a result of the syndrome. Although scintigraphy is 


\section{What is already known on this topic}

Patellofemoral pain syndrome (PFPS) is one of the most common musculoskeletal disorders and is characterised by pain in the front of the knee.

recognised as very sensitive to increased bone turnover, a positive bone scan is not always associated with symptoms. ${ }^{23}$ It is possible that such uptake is caused by a change in physical activity. Our patients had a long history of pain (median 8.4 years) and a low activity level (table 1 ). On the other hand, other studies have reported diffuse uptake on bone scintigraphy in patients suffering from PFPS despite different inclusion criteria. ${ }^{13}{ }^{15} 17$ This could indicate that bone metabolism is involved in approximately half of the patients diagnosed with PFPS and AKP.

Butler-Manuel, ${ }^{13}$ Hejgaard and Diemer, ${ }^{15}$ and Dye and Boll ${ }^{17}$ have reported diffused uptake on bone scintigraphy in $40-55 \%$ of patients with PFPS. The authors, however, interpreted this finding differently. Butler-Manuel ${ }^{13}$ meant that his patients suffered from reflex sympathetic dystrophy, and he used sympathetic blockades in the treatment of his patients. Hejgaard and Diemer ${ }^{15}$ believed that diffuse uptake was secondary to increased intra-medullar pressure and used decompression as the treatment of choice. Dye and Boll ${ }^{17}$ proposed a different interpretation of positive findings on a bone scintigram. They developed a theoretical model of osseous homeostasis where one or more triggering factors may increase remodelling activity in bone, which is detectable with scintigraphy. Diffuse uptake on bone scintigraphy has been interpreted as a change in bone turnover that could be due to ischemia or overuse..$^{21}$

We could speculate that the findings of diffuse uptake on bone scintigraphy in approximately half of the patients suffering from PFPS may indicate regions of ischaemic stress. This is in accordance with Dye et $a l^{8}$ who summarised that the genesis behind PFPS is a loss of homeostasis, particularly in peripatellar soft tissue but also in the intraosseous environment of the patella. The ischaemia could be caused by higher intraosseous pressure, ${ }^{924}$ by redundant axial loading, ${ }^{25}$ or by decreased arterial blood flow. ${ }^{26}$

PFPS, stress fractures, and medial tibial stress syndrome (MTSS) can be visualised on bone scintigraphy. ${ }^{1727} 28$ The appearance of mild increased uptake on bone scintigraphy relates to the mildest form of bone stress and is a sign of accelerated remodelling. Sites where remodelling is occurring contain regions with a temporary loss of bone, measured by dual energy $x$ ray absorptiometry, and show osteopeni. Magnusson et $a^{29}$ concluded that MTSS, with diffusely increased scintigraphic uptake, is associated with low bone mineral density (BMD). The lower BMD was found only in the region corresponding to the pain and diffuse uptake on bone scintigraphy and increased after recovery. Leppälä et a ${ }^{30}$ found significantly decreased BMD in the distal femur, the patella, and the proximal tibia in patients with PFPS. The differences were small and could result from a remodelling process during the resorption phase. This is in accordance with our study and proposes that the proximal tibia could also be involved in this syndrome.

AKP is a symptom, but recently it has been categorised as a distinct syndrome. ${ }^{31}$ The disorder is also called patellalgia, ${ }^{32}$ $\mathrm{PFPS}^{33}$ idiopathic $\mathrm{AKP},{ }^{34}$ patellofemoral malalignment, ${ }^{35}$ patellofemoral arthralgia, ${ }^{36}$ extensor mechanism disorder, ${ }^{37}$ femuropatellar pain syndrome, ${ }^{38}$ patella compression syndrome, ${ }^{39}$ overuse patellofemoral pain, ${ }^{40}$ and previously, chondromalacia patellae. ${ }^{41}$ Most of these terms indicate that the pathophysiology is to be found in the patella or in the
What this study adds

Scintigrams of approximately half of the patients with PFPS will show diffuse uptake in one or more of the bony compartments of the knee joint and radioactive tracer accumulation will occur as often in the proximal tibia as in the patella.

femur. However, we found radioactive tracer accumulation just as often in the proximal tibia $(25 / 48)$ as in the patella (27/48). Some practitioners who find no identifiable background to the pain use the terms AKP as well as patellofemoral pain. These terms are best reserved for describing the patient who has yet to be evaluated. As the proximal tibia may also be a site for homeostatic changes, patellofemoral tibial pain appears to be a suitable term. This is also supported by the clinical picture as our patients did not report subjective complaints of discomfort or pain in a specific region or were tender to palpation at a specific site. ${ }^{19}$ Until the pain mechanism has been more fully explored, a generic term should be used.

In summary, scintigrams of approximately half of the patients with PFPS will show diffuse uptake in one or more of the bony compartments of the knee joint. Radioactive tracer accumulation occurs in the proximal tibia as often as it does in the patella.

\section{Authors' affiliations}

J E Näslund, Department of Physiology and Pharmacology, Karolinska Institutet, Stockholm, Sweden

S Odenbring, Department of Orthopaedics, Hässleholm-Kristianstads Hospitals, Hässleholm, Sweden

U-B Näslund, Näslunds Sjukgymnastik AB, Kristianstad, Sweden T Lundeberg, Department of Rehabilitation Medicine, Karolinska Hospital, Stockholm, Sweden

Competing interests: none declared

\section{REFERENCES}

1 Arrol B, Ellis-Pegler E, Edwards A, et al. Patellofemoral pain syndrome. A critical review of the clinical trials on nonoperative therapy. Am J Sports Med 1997;25:207-12

2 Cutbill JW, Ladly KO, Bray RC, et al. Anterior knee pain: a review. Clin J Sports Med 1997;7:40-5.

3 Kannus $\mathbf{P}$, Aho K, Järvinen $M$, et al. Computerized recording of visits to an outpatient sports clinic. Am J Sports Med 1987; 15:79-85.

4 Lindberg U, Lysholm J, Gillquist J. The correlation between arthroscopic findings and the patellofemoral pain syndrome. Arthroscopy 1986;2:103-7

5 Yates C, Grana WA. Patellofemoral pain - a prospective study. Orthopedics 1986;9:663-7.

6 The International Patellofemoral Study Group. Patellofemoral semantics. Am J Knee Surg 1997; 10:92-5.

7 Dye SF, Stäubli HU, Biedert R, et al. The mosaic of pathophysiology causing patellofemoral pain: therapeutic implications. Operative Tech Sports Med 1999:7:46-54.

8 Dye SF. Patellofemoral pain current concepts: an overview. Sports Med Arthrosc Rev 2001;9:264-72.

9 Arnoldi CC. Patellar pain. Acta Orthop Scan Suppl 1991;244:1-29.

10 Mori Y, Fujimoto A, Okumo $\mathrm{H}$, et al. Lateral retinaculum release in adolescent patellofemoral disorders: its relationship to peripheral nerve injury in the lateral retinaculum. Bull Hosp Jt Dis Orthop Inst 1991;51:218-29.

11 Sanchis-Alfonso V, Roselló-Sastre E. Immunohistochemical analysis for neural markers of the lateral retinaculum in patients with isolated symptomatic patellofemoral malalignment. Am J Sports Med 2000;28:725-31.

12 Merchant AC. Classification of patellofemoral disorders. Arthroscopy 1988:4:235-40.

13 Butler-Manuel PA. Sympathetically mediated anterior knee pain. Acta Orthop Scand 1992;63:90-3.

14 Dye SF. Imaging of the knee. Orthop Rev 1993;22:901.

15 Hejgaard N, Diemer $\mathrm{H}$. Bone scan in patellofemoral pain syndrome. Int Orthop 1987; 11:29-33.

16 Dye SF, Chew MH. The use of scintigraphy to detect increased osseous metabolic activity about the knee. J Bone Joint Surg 1993;75:1388-406. 
17 Dye SF, Boll DA. Radionuclide imaging of the patellofemoral joint in young adults with anterior knee pain. Orthop Clin North Am 1986; 17:249-62.

18 Boegård T, Rudling O, Dahlström J, et al. Bone scintigraphy in chronic knee pain: comparison with magnetic resonance imaging. Ann Rheum Dis 1999;58:20-6

19 Näslund J, Näslund U, Odenbring S, et al. Sensory stimulation (acupuncture) for the treatment of idiopathic anterior knee pain. J Rehabil Med 2002;34:231-8.

20 Loberboym M, Ben Ami D, Zin D, et al. Incremental diagnostic value of ${ }^{99 m} \mathrm{Tc}$ methylene diphosphonate bone SPECT in patients with patellofemoral pain disorders. Nucl Med Commun 2003:24:403-10.

21 McCarthy EF. Histopathologic correlates of a positive bone scan. Semin Nud Med 1997;27:309-20.

22 Minoves M. Bone and joint sports injuries: the role of bone scintigraphy. Nucl Med Commun 2003;24:3-10.

23 Matheson GO, Clement DB, McKenzie DC, et al. Scintigraphic uptake of

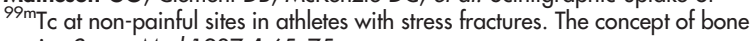
strain. Sports Med 1987;4:65-75.

24 Milmer $\mathrm{O}$, Siebert $\mathrm{CH}$, Schneider $\mathrm{U}$, et al. Patellar hypertension syndrome in adolescence: a three-year follow up. Arch Orthop Trauma Surg 2003; 123:455-9.

25 Otter MW, Qin YX, Rubin CT, et al. Does bone perfusion/reperfusion initiate bone remodelling and the stress fracture syndrome? Med Hypoth 1999;53:363-8.

26 Kirschner MH, Menck J, Nerlich A, et al. The arterial blood supply of the human patella. Surg Radiol Anat 1997;19:345-51.

27 Magnusson HI, Ahlborg HG, Karlsson C, et al. Low regional bone density in athletes with medial tibial stress syndrome normalizes after recovery from symptoms. Am J Sports Med 2003;31:596-600.
28 Murphy E, FitzGerald O, Saxne T, et al. Increased serum cartilage oligomeric matrix protein levels and decreased patellar bone mineral density in patients with chondromalacia patellae. Ann Rheum Dis 2002;61:981-5.

29 Magnusson HI, Westlin NE, Nyquist $F$, et al. Abnormally decreased regional bone density in athletes with medial tibial stress syndrome. Am J Sports Med $2001 ; 29: 712-5$.

30 Leppälä J, Kannus P, Natri A, et al. Bone mineral density in the chronic patellofemoral pain syndrome. Calcif Tissue Int 1998;62:548-53.

31 Lichota DK. Anterior knee pain: symptom or syndrome? Curr Womens Health Rep 2003;3:81-6.

32 Alietti P, Buzzi R, Pisaneschi A. Patella pain. J Sports Trauma Relat Res 1990;12:131-50

33 Davidson K. Patellofemoral pain syndrome. Am Fam Physician 1993:48: 1254-62.

34 Holmes VS Jr, Clancy WG Jr. Clinical classification of patellofemoral pain and dysfunction. J Orthop Sports Phys Ther 1998;28:299-306.

35 Goldberg B. Patellofemoral malalignment. Pediatr Ann 1997;26:32-5.

36 Gerrard B. The patello-femoral pain syndrome: a clinical trial of the McConnell program. Aust J Physiother 1989;35:71-80.

37 Grana WA, Kriegshauser LA. Scientific basis of extensor mechanism disorder. Clin Sports Med 1985;4:247-57.

38 Strobel M, Stedffelt $H$, eds. Evaluation of the femuropatellar joint. In Diagnostic evaluation of the knee. Berlin: Springer, 1990:183-98.

39 Larsson RL, Cabaud HE, Slocum DB, et al. The patella compression syndrome: surgical treatment by lateral retinacular release. Clin Orthop 1979;134:156-67.

40 Finestone A, Radin EL, Lev B, et al. Treatment of overuse patellofemoral pain. Prospective randomized controlled trial in military setting. Clin Orthop 1993:293:208-10

41 Aleman O. Chondromalacia post-traumatica patellae. Acta Chir Scand 1928;63:149-90

\section{ELECTRONIC PAGES}

\section{Online original article and case report}

$\mathrm{T}$ he following electronic only articles are published in conjunction with this issue of BJSM (see also pages 136 and 158)

\section{Effect of sporting activity on absenteeism in a working population}

S G van den Heuvel, H C Boshuizen, V H Hildebrandt, et al Objectives: To determine the effects of sporting activity on absenteeism in a working population.

Methods: Data were used from a prospective cohort study in a working population with a follow up period of 3 years and were collected with yearly questionnaires or collected from company records. Complete data on absenteeism, sporting activity, and potential confounders were collected for 1228 workers. ANOVA was used to test differences in frequency and duration of absenteeism, correlations were computed to measure the association between number of sporting years (divided by age) and frequency and duration of absenteeism, and survival analysis, according to the Cox proportional hazards model, was used to test differences in relative risk at absenteeism and recovery. All analyses were adjusted for age, gender, smoking, and alcohol consumption, and were stratified for employees with sedentary and with more active jobs.

Results: ANOVA showed a statistically significant higher mean duration of absenteeism among employees not practicing sports, of approximately 20 days over a period of 4 years. The survival analysis showed an increased relative risk at absenteeism (relative risk (RR) 1.09; confidence interval (CI) 1.01 to 1.18 ) and a decreased relative risk at recovery (RR

0.90; CI 0.85 to 0.95 ) for employees not practicing sports. The effect of sporting activity is larger in employees with sedentary work. No associations were found between number of sporting years and absenteeism.

Conclusion: Employees practicing sports take sick leave significantly less often than their colleagues not practicing sports, while their periods of sick leave are shorter, especially when their work is sedentary.

(Br J Sports Med 2005;39:e15) http://bjsm.bmjjournals.com/ cgi/content/full/39/3/e15

\section{Multiple osteochondroses and avulsion fracture of anterior superior iliac spine in a soccer player M N Doral, S T Aydog, O Tetik, et al}

Apophysitis describes a chronic traction injury at the insertion site of a tendon. There is a gradual onset of pain with no clear history of injury. Without adequate preventive methods, an avulsion fracture may result. The case is here reported of an apophyseal avulsion fracture of the anterior superior iliac spine in an adolescent caused by playing football before the end of treatment for apophysitis. An open reduction and internal fixation was performed followed by a rehabilitation programme. No complications occurred, and the patient had returned to his previous level of sporting activity after six weeks.

(Br J Sports Med 2005;39:el6) http://bjsm.bmjjournals.com/ cgi/content/full/39/3/e16 